\title{
A Study on Design of a Drone for Transportation in the Agricultural Sector
}

\section{Muhammad Faris M.Nor ${ }^{1}$, Mohd Fahrul Hassan ${ }^{1 *}$}

${ }^{1}$ Faculty of Mechanical and Manufacturing Engineering

Universiti Tun Hussein Onn Malaysia (UTHM), Parit Raja, 86400, MALAYSIA

*Corresponding Author

DOI: https://doi.org/10.30880/jsmt.2021.01.01.001

Received 24 August 2021; Accepted 11 October 2021; Available online 15 December 2021

\begin{abstract}
A drone is a fast-growing technology that has been used in many applications in the world. The drone also is a new solution for the transportation process in the agricultural sector. The primary purpose of this project is to explore the potential of drone or Unmanned Aerial Vehicle (UAV) to reduce the dependence on fossil-fueled vehicles to transport the crops within the farm and from the farm to the seller. The use of drones will create lower emission of carbon dioxide and toxic gases that are usually generated by fossil-fueled vehicles. Besides, this research is also essential to reduce the health issues that currently appear from agriculture activities. The objective of this project is to determine the parameters to design a suitable drone for transportation in the agricultural sector. In addition, the design of the drone must be able to carry a maximum of $10 \mathrm{~kg}$ of payload, which can be analyzed by simulation and analysis. The simulation and analysis are performed by SolidWorks software. The conceptual design of the drone is proposed by following the George E. Dieter model of the design process. In addition, a simulation on the strength of the drone components and analysis on the thrust of the motor have been conducted to verify the proposed drone design concept based on the determined parameters. The cost estimation of the drone is about RM17683.65 and the overall weight is $26.823 \mathrm{~kg}$. In conclusion, the drone design concept for transportation in the agricultural sector is proposed as a preliminary study for future works.
\end{abstract}

Keywords: Drone, transportation, agricultural sector, concept

\section{Introduction}

The agricultural sector is one of the most essential sectors in every country, including Malaysia. National agriculture sector can be presented in three main sub-sector which are crops, livestock and fisheries. The agricultural sector contributed 7.3\%, which is about RM 99.5 billion to Malaysia Gross Domestic Product (GDP) in 2018 [1]. In Malaysia, crops are the primary sub-sector in the agricultural sector compared to the livestock and fisheries sub-sector. Types of crops have been clustered by the Department of Agriculture (DOA) which are fruits crops, industrial crops, herbs and spices, vegetables and cash crops [2]. The examples of main fruits crops are durian, banana, rambutan, pineapple, and watermelon. The main producer of fruit crops is Johor. Vegetables and cash crops gained popularity within this decade because a lot of research and innovation has been performed and make it an essential crop in agriculture activities. Examples of primary vegetables and cash crops are sweet corn, brassica, spinach, cucumber, lettuce, cabbage, and sweet potato which are generalized as food crops sub-sector. Even though the types of crops, number of planted areas and location of major producers are different, the method to transport the crops or other agriculture activities is still the same. The crops are commonly transported using traditional methods such as human energy or force and few types of vehicles such as trucks, rail, ships and airplanes, depending on the distances of the destination and the process or the activities. Transportation in the agricultural sector is needed in many processes, neither pre-plant nor post-harvest, when 
transporting crops within the farm and transporting crops from farm to the dealer or market places. The types of goods or crops, the quantity and the cost also will affect the selection of transportation.

The main concern of this research is to increase the efficiency of transportation by using the drone. The transportation drone in the agricultural sectors can reduce the need for fossil fueled vehicles. Less fossil fuel utilization means low carbon emission. Besides from an environmental view, it also lessens the workload to the labour to transport heavy crops from harvesting plot to collection centre. Therefore, healthcare of the labourers is emphasized. Furthermore, the use of drones for transporting crops is fast and is an efficient way because aerial vehicles can move autonomously or remote controlled if there are any emergencies besides the low traffic problem.

\subsection{Environmental Aspect}

Most agriculture activities still use traditional methods such as using human force in planting, irrigation or watering process, harvesting and transporting the crops. Transportation in the agricultural sector is a crucial process because it affects in the short term and long terms, such as health, environment and nature. Some agricultural activities use human energy to transport crops from crop plot to a collection centre in health aspects. This process becomes more challenging at different geographical surfaces such as hilly terrain. The farmers will have health issues in the long term of working [3]. Transportation of crops for further distance needs mechanized transport such as trucks, rail, and cars which using fossil fuels to operate. High use of fossil fuel might cause other problems such as carbon dioxide (C02) emissions and air pollution, leading to health problems such as cancer and lung problems. In addition, these vehicles will also lead to noise pollution, especially big trucks. The objectives of this study are to identify the parameters and generate a design of drone for transportation in the agricultural sector and also to analyse the designed drone concept for lifting a load with a maximum of $10 \mathrm{~kg}$.

\section{Methodology}

\subsection{Design Process}

The design process of this research is made by referring to the George E. Dieter Design Process model. The design process model has eight stages from three main phases. The three main phases in the design process model are conceptual design, embodiment design and detail design [4].

\subsection{Data Collection and Analysis}

Data collection is an important aspect in the first phase of the design process to achieve the objective for this project. For this research, the data is collected from the potential customers by survey. Example of data is the parameters to design the drone. The parameters are needed to verify the problem statement of this research besides to generate the ideas of the drone concept from collected information. Before the drone concept is selected, the data is analyzed and interpreted into the form of House of Quality (HOQ) which is a method to translate the customer requirement, specification and criteria that must be included into the product by creating a relationship matrix [5]. Then, the product design specification (PDS) can be established according to the House of Quality information. Specification, technical data, and functionality are the information that can be gathered in this process in order to have deeper understanding and knowledge of the product such as drone technology. After all possible concepts are generated by following the activities sequence, all the concepts must be evaluated and analysed by using Weighted Rating Matrix. Highest rating of the concept will be selected as the drone design.

\subsection{Engineering Analysis}

Engineering analysis of this study is performed in the embodiment design phase. This phase includes the process for the material selection, simulation of the product strength, size and shape of the product. The product architecture, configuration design and the parametric design of the drone is generated to analyze the drone design that is made purposely to set the correct and accurate values for the design variable. This will produce the best possible design in terms of performance, cost and other aspects.

Arrangement of the physical element such as components of the product is combined to produce a rough geometric layout of the product. The interaction between all the elements in the product architecture also need to be identified from the geometric layout. The modelling and simulation process can be conducted by using SolidWorks software to ensure the design and material selection fulfil the customer requirement. The simulation of the strength of important components is performed to determine the reliability and durability of the drone when carrying the maximum load of $10 \mathrm{~kg}$. The weight and cost estimation of the product was also conducted as part of the engineering analysis. 


\section{Results and Discussion}

The conceptual design of the drone for transportation in the agricultural sector is generated based on the requirements and criteria gathered from the data collection. Figure 1 shows the design of the drone that consists of several subassemblies. The frame, the propulsion system, the landing gear, the cover and the power source are the sub-assemblies of the drone. Frame is a combination of three plates that acts as the main body, motor holder, four arms that link the propulsion system and the support rod that is mounted between middle and bottom plate. The coaxial propulsion system is chosen for the drone because the configuration can produce more thrust to the drone which is suitable for a heavy lift drone. The X-shape drone frame can provide good stability for the drone [5].

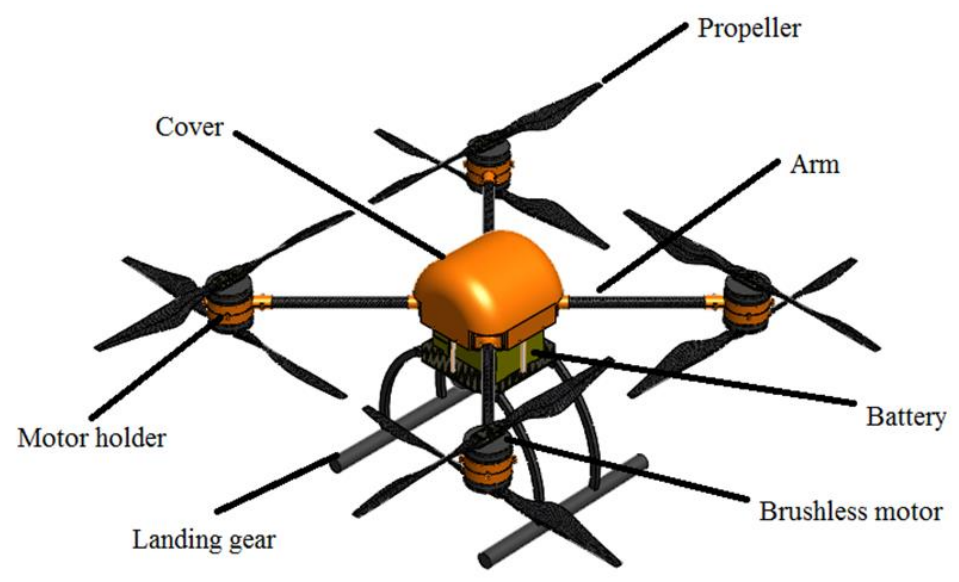

Fig. 1 - The geometric layout of the drone

\subsection{Material Selection}

Material of the components play an important role to avoid any damage or failure when operating the drone. Generally, a drone must be lightweight so that the drone is able to fly and operate at a certain altitude and is also able to withstand high load. Therefore, the material properties of the drone must be suitable to produce a light weight but high strength drone. Table 1 shows the material of each component that has been selected from the data collection and analysis.

Table 1 - Material of the component

\begin{tabular}{cc} 
Component & Material selection \\
\hline $\begin{array}{c}\text { Top plate, Middle plate, Bottom plate, Bottom } \\
\text { propeller clamp, Top propeller clamp }\end{array}$ & Carbon Fibre Composite \\
Arm, Right propeller, Left propeller & Carbon Fibre Reinforced Polymer \\
Arm mount 1, Arm mount 2, Motor holder, Cover & Acrylonitrile butadiene styrene (ABS) \\
Support rod & ASTM 1060 Steel \\
\hline
\end{tabular}

\subsection{Component Analysis}

Arm is a part that links the body of the drone and the propulsion system. It should have high strength but lightweight. Therefore, a carbon fiber hollow rod is selected to be used for the arm. The load from two propulsion systems may result in damage to the arm. Therefore, a simulation is performed to analyze the strength of the arm. As shown in Table 2, the maximum stress that is recorded by the simulation at the arm is $6.221 \mathrm{x} 106 \mathrm{~N} / \mathrm{m}^{2}$ and the value is lower than the yield strength which is $1.23 \times 109 \mathrm{~N} / \mathrm{m}^{2}$. The maximum stress occurs at the point the arm is mounted at the body. Displacement of the arm after the load is subjected is performed to determine the crucial region of the arm that may deflect due to the load. Table 2 also shows the maximum displacement is $1.825 \times 10^{-1} \mathrm{~mm}$ or $0.1825 \mathrm{~mm}$ can occur at the end of the load. 
Even though the maximum displacement recorded, the value of its displacement is small. The strain simulation result of the arm shows in Table 2 recorded that the maximum strain value at the arm is the same region of the maximum stress value is recorded. The maximum strain recorded using the simulation is $4.6611 \times 10^{-5}$ while the lowest strain recorded is $6.358 \times 10^{-14}$.

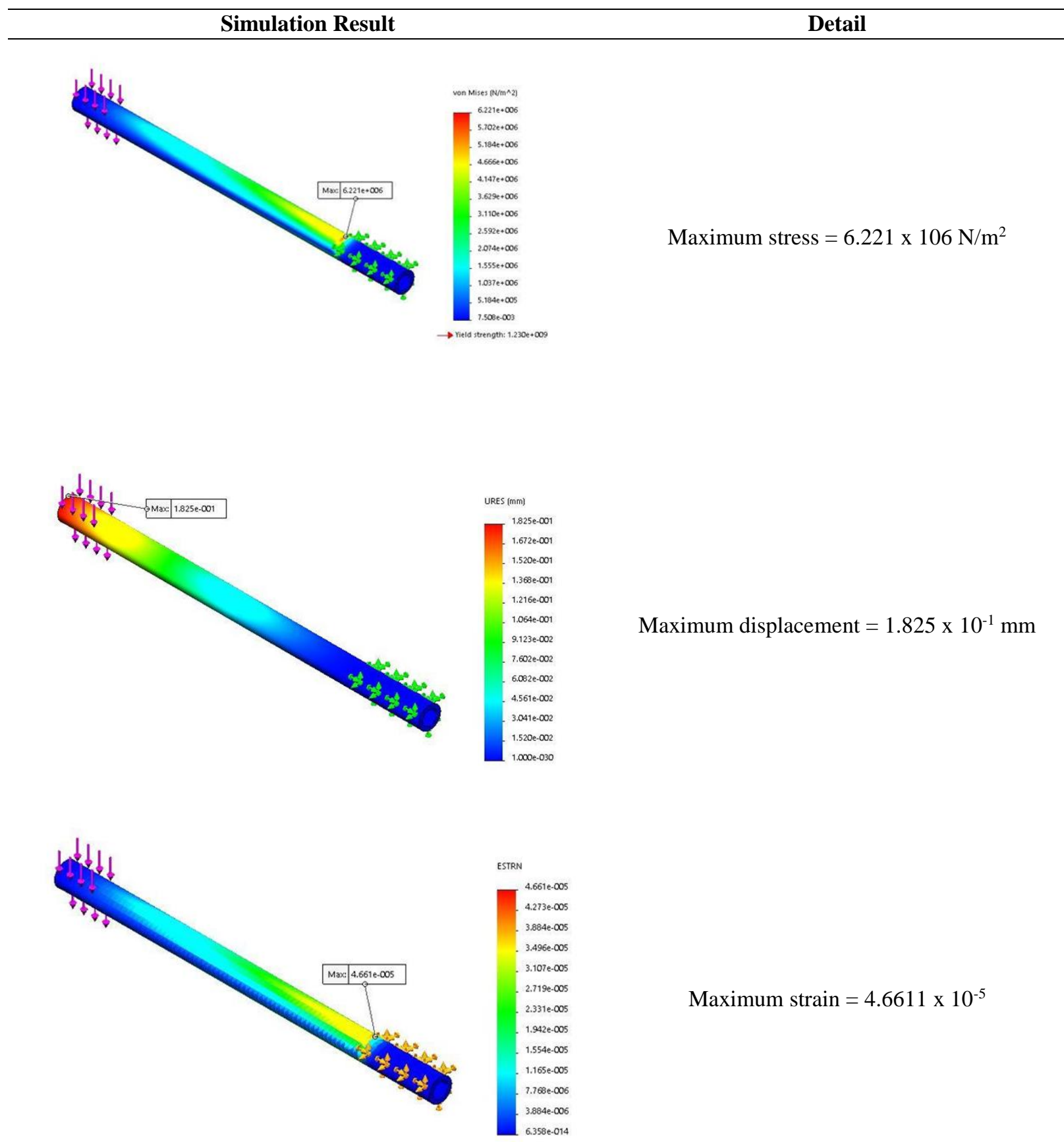

The landing gear of this drone acts as a support structure to the whole frame. The landing gear are made of high strength material with less density but can be flexible under high load. The flexibility of the landing gear acts as a damper to absorb the impact when landing the drone. 


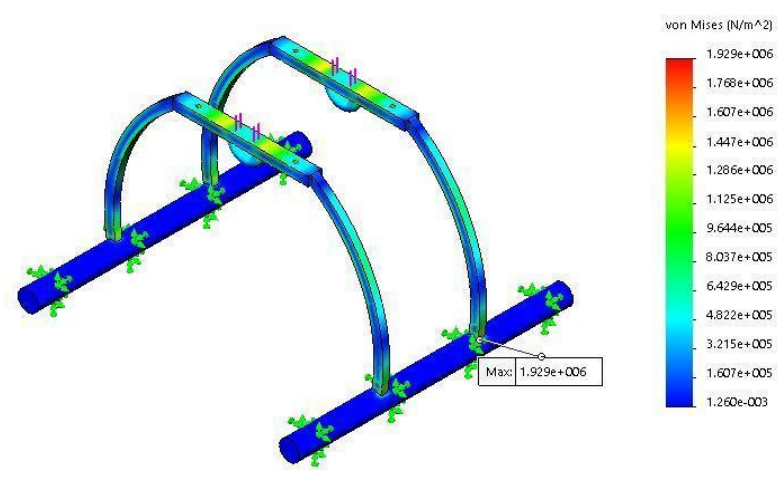

Fig. 2 - Stress analysis of the landing gear

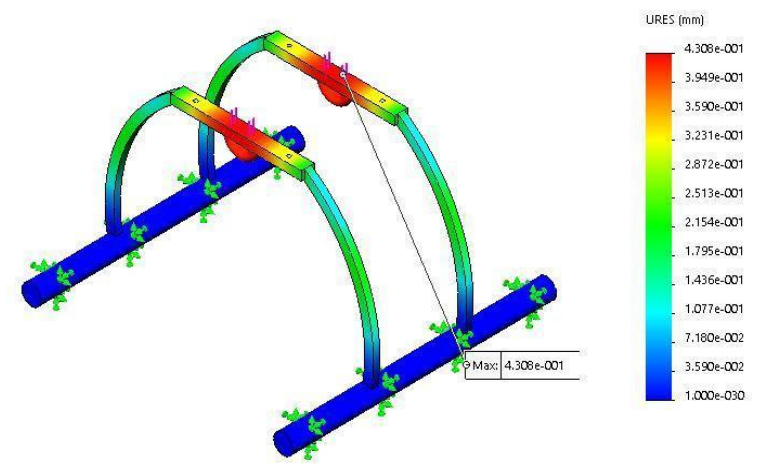

Fig. 3 - Displacement analysis of the landing gear

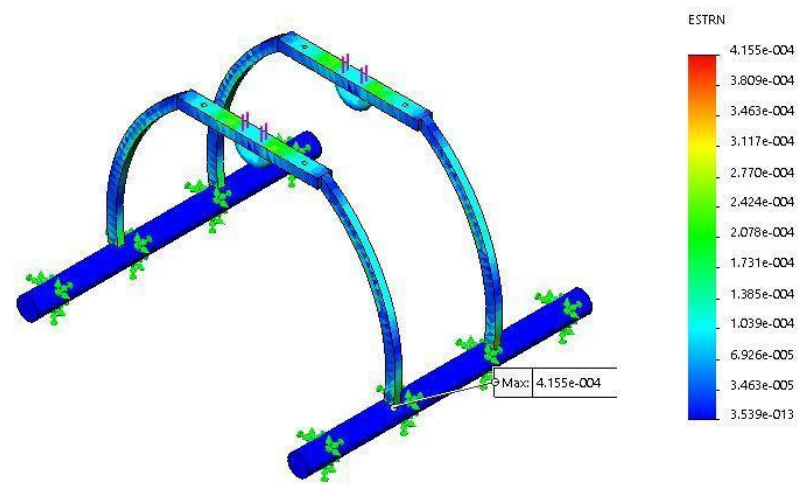

Fig. 4 - Strain analysis of the landing gear

The stress simulation result of the landing gear shown in Figure 3. The maximum stress recorded at the landing gear is $1.929 \times 10^{6} \mathrm{~N} / \mathrm{m}^{2}$ at the lower region of the component. Apart from that, the maximum displacement occurring at the landing gear is $4.308 \times 10^{-1} \mathrm{~mm}$. The maximum displacement occurs at the centre of the landing gear and also the region of the load is applied. The maximum strain occurring at the landing gear is $4.308 \times 10^{-1}$. As shown in Figure 4.37, the maximum strain occurs at the same region as the maximum stress of the landing gear is recorded. The minimum value of the strain recorded at the landing gear is $3.539 \times 10^{-13}$.

The motor of the drone is selected based on the thrust produced by the motor. The thrust is the force produced by the motor to generate lift. To generate lift, the ratio of thrust and the load applied is 3:1 which means the total thrust at half of the power is three times bigger than the load. The number of motors for the drone is eight units. 


$$
\begin{gathered}
m=\text { mass of load } \\
m=10 \mathrm{~kg}
\end{gathered}
$$

Thrust required, $T_{\text {req }}$

$$
T_{\text {req }}>3 \times 10 \mathrm{~kg}
$$

Therefore, the torque required per motor is

$$
\begin{gathered}
T_{\text {req }}=\frac{30 \mathrm{~kg}}{8 \mathrm{unit}} \\
T_{\text {req }}=3.75 \mathrm{~kg} / \text { unit } \\
T_{\text {req }}=3750 \mathrm{~g} / \text { unit }
\end{gathered}
$$

\subsection{Drone specification}

The cost and weight of the drone is estimated by analyzing it using SolidWorks software. The cost and weight of the drone is important because both of them are included in the main product specification. After the calculation is made, the overall material cost for the drone is RM17683.65 while the overall weight of the drone without load is $27.5 \mathrm{~kg}$. As a customer requirement, the drone should be compact size and easy to operate. Therefore the maximum dimension of the drone is less than 2 meter. Table 2 shows the details of the drone specification.

Table 2 - The product specification of the drone

\begin{tabular}{cc}
\hline Product Specification & Details \\
\hline Dimension (L x W x H) & $1855 \mathrm{~mm} \times 1855 \mathrm{~mm} \times 622 \mathrm{~mm}$ \\
Wheelbase & $1361 \mathrm{~mm}$ \\
Overall weight & $27.5 \mathrm{~kg}$ \\
Overall Cost & RM17683.65 \\
\hline
\end{tabular}

\section{Conclusion}

In conclusion, the objectives for development of the drone for transportation in the agricultural sector is achieved based on the various literatures and methods. The parameters of the drone design is gathered from the online survey. The final design of the 3D CAD model of the drone is created by using SolidWorks software based on the George E. Dieter design process. The design of the drone also has been analyzed to make sure the drone is able to lift about $10 \mathrm{~kg}$ of payload so that the functionality criteria of the drone is achieved. The simulation and the analysis of the drone that was performed shows the selected material of the drone is able to withstand $10 \mathrm{~kg}$ of load subjected to the parts of the drone. The dimension of the drone is within the range needed which is 1.8 meter for the length and the width of the drone. while the drone has $0.6 \mathrm{~m}$ of height from the ground. The drone design is expected to minimize the need for fossil fuel vehicles for the transportation process in the agricultural sector because the motor used as a propulsion system is more efficient and produces low carbon emission.

For further development of the drone for transportation in the agricultural sector each component of the drone should be lightweight especially for the three major plates should be minimized without reducing the strength of the component. The total weight of the final design of the drone is heavier than recommended weight and compared to available heavy lift drones in the market. Besides, there is limited information for the actual design of the propeller by the manufacturer. Therefore, precise data from the manufacturer might be the solution for this limitation. Another element that can be improved is for the material data for carbon fiber. The data of the types of carbon fiber material and its specific application needed to stimulate the design strength precisely and accurately. Furthermore, the locking mechanism of the cover can be improved by creating a simple and quick release mechanism for the cover. Quick release of the cover will enable the operator to maintain the electronic component of the drone in a shorter period. Lastly, the hydraulic pump system should be applied at landing gear which is the best damper system compared to the flexibility of the material to support the drone when landing. 


\section{Acknowledgement}

The author would like to thank the Faculty of Mechanical and Manufacturing Engineering, Universiti Tun Hussein Onn Malaysia (UTHM) for its support.

\section{References}

[1] Mahidin, D. M. U. (2019). Department of Statistics Malaysia Press Release. Department of Statistics Malaysia, November, 5-9

[2] DOA (Department of Agriculture). (2018). Vegetables and Cash Crops Statistics Malaysia. Department of Agriculture Malaysia, 26. http://www.doa.gov.my/c/document_library/get_file?uuid=816658e9-f178-4d16-a896$111 \mathrm{ca3} 1244 \mathrm{ff} \&$ groupId $=38257$

[3] Coman, M. A., Marcu, A., Chereches, R. M., Leppälä, J., \& Van Den Broucke, S. (2020). Educational interventions to improve safety and health literacy among agricultural workers: A systematic review. International Journal of Environmental Research and Public Health, 17(3), 1-15

[4] Dieter, G. E., \& Schmidt, L. C. (2013). Engineering Design 5th Edition (Vol. 5)

[5] Erceg, A., Činčurak Erceg, B., \& Vasilj, A. (2017). Unmanned aircraft systems in logistics - legal regulation and worldwide examples toward use in Croatia. Business Logistics in Modern Management, 0(0), 43-62 